\title{
Editorial
}

Estamos chegando ao final do triênio (2010-2012) de avaliação dos Programas de Pós-Graduação pela Coordenação de Aperfeiçoamento de Pessoal de Nível Superior (CAPES), e a corrida pela produção toma grande espaço entre os pesquisadores. Nestes últimos meses temos recebido telefonemas e e-mails de autores perguntando sobre a situação dos artigos, sobre a possibilidade de ainda enviarem artigos para serem publicados neste ano e outras demandas ligadas à possibilidade de mostrar produção.

O produtivismo faz parte da nova configuração das universidades, principalmente dos Programas de Pós-Graduação que são avaliados, sobretudo, pelo que produzem. A lógica produtivista do mercado invade as universidades e tem contribuído para o adoecimento dos professores. Em pesquisa realizada por Borsoi (2012), com 96 professores de universidades públicas vinculados a Programas de Pós-Graduação, os participantes consideram que são as políticas e metas criadas pelas instituições financiadoras e administrativas as responsáveis pela busca da produtividade. Dentre os participantes, segundo a autora, $78(81,3 \%)$ relataram ter procurado atendimento médico el ou psicológico nos últimos dois anos. Produtivismo, aliado ao sofrimento, povoa, então, o espaço acadêmico.

A pressão por produção é muito grande, o que acaba, segundo Bianchetti e Valle (2011), comprometendo a qualidade daquilo que é produzido. Os autores comentam que, em pesquisa realizada com 74 coordenadores de programas e orientadores vinculados a Programas de Pós-graduação stricto sensu avaliados pela CAPES e com 16 investigadores ligados a universidades da União Européia, com relação à produção acadêmica, "(...) os depoimentos dos entrevistados evidenciam o comprometimento da qualidade do que é produzido pela pressão de publicar: 'tornamo-nos especialistas em amontoar fragmentos', 'requentamos diferentes versões do mesmo texto' ", (p. 6-7), informam os participantes. Se Freud, Marx, entre vários expoentes de diferentes ciências, levaram anos para elaborar e publicar os seus achados, hoje, no prazo de três anos, temos que dar conta de explicar fatos que envolvem a cognição e afetos, por exemplo, do psiquismo do homem atual.

Mediante tal realidade, convivemos, ainda, com o esvaziamento dos conteúdos, conforme propõem Kuenzer e Moraes (2005). Com a pressão pela produção em grande escala, com uma rapidez característica de um mercado que a toda hora quer lançar novos produtos, pesquisadores nem sempre conseguem fazer elaborações mais profundas sobre aquilo que estão pesquisando. As autoras comentam que tal fato conduz a um nivelamento "reduzindo o cognoscível à experiência sensível" (p. 1352), levando a um praticismo e a um pragmatismo.

Isto significa compreender que o método de produção do conhecimento é um movimento do pensamento que, no e pelo pensamento, parte da apreensão de um primeiro nível de abstração composto pela vital, empírica, caótica e imediata representação do real, e tem, como ponto de chegada, formulações conceituais cada vez mais abstratas. Estas, de volta ao empírico e imediato ponto de partida, podem apreendê-lo como totalidade ricamente articulada e compreendida, mas também como prenúncio de novas perspectivas, apenas intuídas, que levam o presente a novas buscas e formulações a partir da dinâmica histórica que articula o já conhecido ao presente e anuncia o futuro. (Kuenzer \& Moraes, 2005, p. 1353)

O que se constata, muitas vezes, em artigos publicados, é uma descrição dos fatos, e não sua explicação, haja vista que trabalhar dessa forma exigiria muito tempo; tempo que não é possível "perder" quando o mundo caminha muito rápido e a premência quantitativa de produção paira sobre os pesquisadores e estudiosos. 
Não estamos, com estas reflexões, querendo desanimar nosso leitor acerca das produções que apresentamos neste número da revista. Com certeza, encontrará artigos de qualidade, que contribuirão para o desenvolvimento da ciência. No entanto, temos que pensar no custo que tais produções estão trazendo para a saúde mental dos pesquisadores e caminhar, cada vez mais, na defesa da necessidade de investimento para que possamos ter tempo e condições objetivas para criar, para nos apropriarmos do que já existe e produzirmos novas objetivações.

Boa leitura.

\section{Marilda Gonçalves Dias Facci}

Editora Responsável

\section{Referências}

Bianchetti, L., \& Valle, I. R. (2011). Produtivismo acadêmico e condições de vida/trabalho de pesquisadores brasileiros e europeus. Anais do XXV Simpósio Brasileiro e II Congresso Ibero-americano de Política e Administração da Educação. Recuperado: 19 nov. 2012. Disponível: http://www.anpae.org.br/simposio2011/cdrom2011/PDFs/ trabalhosCompletos/comunicacoesRelatos/0301.pdf.

Borsoi, I. C. F. (2012). Trabalho e produtivismo: saúde e modo de vida de docentes de instituições públicas de Ensino Superior. Cadernos de Psicologia Social do Trabalho, 15(1), 81-100.

Kuenzer, A. Z., \& Moraes, M.C. M. (2005). Temas e tramas na pós-graduação em educação. Educação e Sociedade, 26(93), 1341-1362. 